Article

\title{
External and Total Hip Rotation Ranges of Motion Predispose to Low Back Pain in Elite Spanish Inline Hockey Players
}

\author{
Antonio Cejudo 1,2 (D) , Víctor Jesús Moreno-Alcaraz ${ }^{1,2} \mathbb{D}^{\mathbb{D}}$, Ricardo Izzo ${ }^{2,3} \mathbb{D}^{\mathbb{D}}$, \\ Fernando Santonja-Medina ${ }^{2,4,5, *}$ and Pilar Sainz de Baranda ${ }^{1,2, *(\mathbb{C})}$
}

1 Department of Physical Activity and Sport, Faculty of Sport sciences, Regional Campus of International Excellence "Campus Mare Nostrum", University of Murcia, 30720 San Javier (Murcia) C.P., Spain; antonio.cejudo@um.es (A.C.); victorjm@um.es (V.J.M.-A.)

2 Sports and Musculoskeletal System Research Group (RAQUIS), University of Murcia, 30720 Murcia, Spain; riccardo.izzo@uniurb.it

3 Dipartimento di Scienze Biomolecolari, Scuola di Scienze Motorie, Università degli Studi, 61029 Urbino C.P., Italy

4 Department of Surgery, Pediatrics, Obstetrics and Gynecology, Faculty of Medicine, Regional Campus of International Excellence "Campus Mare Nostrum”, University of Murcia, 30100 Murcia C.P., Spain

5 Traumatology and Orthopedic Surgery Service, Virgen de la Arrixaca University Clinical Hospital, 30120 El Palmar (Murcia) C.P., Spain

* $\quad$ Correspondence: santonja@um.es (F.S.-M.); psainzdebaranda@um.es (P.S.d.B.); Tel.: +34-868-88-7159 (F.S.-M.); +34-868-88-7876 (P.S.d.B.)

Received: 27 April 2020; Accepted: 25 June 2020; Published: 6 July 2020

\begin{abstract}
Low back pain (LBP) is a common ailment in competitive athletes. Although the association between limited range of motion (ROM) and prevalence of LBP has been widely investigated in other sports, there is no research about this topic in inline hockey (IH). The main purposes of this study in IH players were (1) to analyze the association between hip ROM and LBP and (2) to establish a diagnostic cutoff for ROM of high risk of LBP. Twenty elite IH players from the two Spanish National Teams (male and female) were assessed for passive maximum hip ROMs; the movement evaluated were the hip external [HER] and internal [HIR] rotation, hip flexion with flexed [HF-KF] and extended [HF-KE] knee, hip adduction with flexed hip [HAD-HF], hip abduction with neutral [HAB] and flexed [HAB-HF] hip, and hip extension [HE]. LBP was retrospectively monitored for the last 12 months before the date of ROM assessment by using a questionnaire. The data were analyzed via a binary logistic regression and receiver operating characteristic curves. The $70 \%$ of players had developed LBP during the retrospective study period. Significant differences between LBP group and asymptomatic group for HER $(p=0.013$, $\mathrm{d}$ [Cohen's effect size] $=1.17)$ and hip total rotation [HTR] $(p=0.032$, $\mathrm{d}$ [Cohen's effect size] $=1.05)$ were observed. The cutoff points with the greatest discriminatory capacity were $56.5^{\circ}$ for HER and $93^{\circ}$ for HTR ROMs.
\end{abstract}

Keywords: assessment; ROC curve; ROM-SPORT battery; injury prevention; back pain

\section{Introduction}

The popularity of inline hockey $(\mathrm{IH})$ has increased in Spain over the last few years, which is reflected in an increase in the number of federal licenses, national leagues, and sports teams [1]. The increased 
participation of IH players is likely to lead to an increase in the prevalence of injuries [2]. The injuries reduce athletic performance and produce lost time of training and competition for long periods [3-5].

Previous studies have correlated inline hockey (IH) with a high risk of sport injury [3-5]. Hutchinson et al. [4] and Moreno-Alcaraz, Cejudo, and Sainz de Baranda [3] showed an estimated game injury rate of 139 and 300 injuries per 1000 athlete-exposures, respectively. Varlotta et al. [5] reported a game injury rate of 304.9 injuries per 1000 game hours. Lacerations, contusions, strains, and sprains are the most prevalent injuries in professional IH players [3-5]. The most frequently injured body regions are the head/neck, shoulder, knee, ankle, and back [3-5]. The most prevalent injuries in professional IH player are knee sprains and lumbosacral sprain [5] and lower trunk contusions [3]. In addition, previous epidemiological data of injuries in IH showed the lumbar spine to be one of the body sites frequently affected, especially via non-contact mechanisms [4-6]. Although, the lumbosacral region is one of the most affected regions in IH-related injuries, little is referred in the literature to the incidence of low back pain (LBP).

The LBP is a very common ailment in competitive athletes [7-10]. Given the biomechanical relationships between the hip, pelvis, and spine, especially the multiple shared muscles (psoas, quadratus lumborum, erector spinae, gluteus maximus, etc.), the hip joint has been considered as a main contributor to LBP [11-13]. It has been demonstrated that restricted range of motion [ROM] increases the risk of injury in athletes. One of the most studied is the association between the restricted hip flexion with extended knee (hamstring tightness) and the LBP in tennis players [14], soccer players [15], and runners [16]. The limited hip extension ROM [17-19] and hip internal rotation ROM or hip total rotation ROM was associated with LBP in professional tennis players [10,14], professional golfers [9], athletes of a rotation-related sports [20], amateur golfers [21], and judo athletes [22]. Also, several studies have found relation between LBP and limited hip internal and external rotation and hip total rotation in the non-athletic population of different ages and sex [23-26]. In this sense, asymmetric (side-to-side) hip rotation ROM is also a risk factor for LBP in different sports $[9,21,24,27-29]$. The importance of the association between LBP and hip rotation ROMs is based on the hypothesis that a limited hip ROM results in compensatory motions of the lumbopelvic region. These compensatory motions generate an increase of the loads and stress in the join tissues of the lumbopelvic region and, as a consequence, produce eventual LBP symptoms $[9,25,26,30]$. All these studies show a significant relationship between limited hip ROM and LBP, but the muscle groups involved in this relationship remain unclear. Clinical and sports professionals hold the supposition that the tightness of muscles inserted in the pelvis (such as the iliopsoas, gluteus maximus, hip adductors, or piriformis) alters the pelvis disposition and the spinal morphotype and, therefore, predisposes to LBP [11]. Although the association between limited ROM and prevalence of LBP has been widely investigated in other sports [20,31-37], there is no research about this topic in IH.

Regarding the technical skills of IH, skating is the most important skill and represents a specific pattern of movement of this sport. Skating stride requires good levels of ankle plantarflexion and dorsiflexion, knee flexion and extension, hip extension and flexion, hip adduction and abduction, and hip external and internal rotation [38-40]. The repetition of skating movements may cause certain musculoskeletal adaptations in IH players such as muscular imbalances, tightness, and asymmetry, causing abnormal pelvis and spinal sagittal alignment and predisposing to LBP [41-46].

However, it is unknown which movements are affected by these negative adaptations in IH and which modified movements are in relation with LBP.

Considering all the above mentioned, the starting hypothesis was that IH players with LBP would have less hip ROM and more asymmetry than asymptomatic IH players. Thus, the main purposes of this study in IH players were (1) to analyze the association between hip ROM and LBP and (2) to establish a diagnostic cutoff for ROM of high risk of LBP. 


\section{Method}

This investigation was a retrospective cohort study of LBP in IH players. The association of demographic data, training regimen, and hip ROMs measures with the incidence of LBP in elite Spanish IH players was examined. This study was performed in IH players that displayed LBP during the last 12 months $(n=14)$ and in IH players without history of LBP during this period $(n=6)$. Finally, we established cutoff values for the associated variables that identify high risk of LBP.

\subsection{Participants}

The participants of these study were IH players of the Spanish National Team who took part in the preparative technical meeting (or training camp) prior to the Roller Games World Championship in Nanjing in 2017. The recruitment lasted the first three days of the technical meeting. Twenty-six elite Spanish $\mathrm{IH}$ volunteer players (13 males and 13 females) between the ages of 18 and 29 years (22.50 \pm 2.89 year) participated in the study. The sample was homogeneous in potential confounding variables, except in training days $(p=0.31)$ and training months $(p=0.007)$ per year (Table 1$)$. The training volume defined as "Training hours during the last 12 months" was calculated using the formula: Training hours $\times$ day $\times$ weekly training days $\times 4$ weeks per month $\times$ months per year [47-49]. None of the participants was involved in a systematic and specific stretching regimen in the previous six months. Besides, the participants did not usually perform stretching exercises daily during their warm-up or cool-down phases.

Table 1. Demographic and training regimen data of the Spanish National Teams' inline hockey players.

\begin{tabular}{cccccc}
\hline Variable & Male $(\boldsymbol{n = 1 0 )}$ & Female $(\boldsymbol{n = 1 0 )}$ & $\boldsymbol{p}$-Value & Effect sizes Cohen's d $^{\text {a }}$ & Total $(\boldsymbol{n}=\mathbf{2 0})$ \\
\hline Age (years) & $22.30 \pm 2.54$ & $22.70 \pm 3.33$ & 0.684 & -0.1351 (trivial) & $22.50 \pm 2.89$ \\
Body mass $(\mathrm{kg})$ & $71.87 \pm 9.64$ & $66.83 \pm 9.20$ & 0.247 & 0.5349 (small) & $69.35 \pm 9.53$ \\
Body Height $(\mathrm{cm})$ & $1.73 \pm 0.05$ & $1.66 \pm 0.05$ & 0.005 & 1.4000 (large) & $1.69 \pm 0.06$ \\
Body mass index $\left(\mathrm{kg} / \mathrm{m}^{2}\right)$ & $23.96 \pm 2.77$ & $24.32 \pm 2.88$ & 0.971 & -0.1274 (trivial) & $24.14 \pm 2.76$ \\
Years of experience & $14.20 \pm 2.97$ & $12.90 \pm 3.98$ & 0.165 & 0.3702 (small) & $13.55 \pm 3.49$ \\
Training months/year & $11.20 \pm 0.92$ & $10.00 \pm 0.00$ & 0.007 & 1.8446 (large) & $10.60 \pm 0.88$ \\
Training days/week & $2.80 \pm 0.42$ & $2.80 \pm 1.03$ & 0.631 & 0.0000 (trivial) & $2.80 \pm 0.77$ \\
Training hours/week & $5.40 \pm 2.27$ & $5.00 \pm 1.83$ & 0.971 & 0.1940 (trivial) & $5.20 \pm 2.02$ \\
\hline
\end{tabular}

Data are expressed as mean \pm standard deviation; ${ }^{a}$ Effect size was classified as trivial or no effect (SMD $\left.<0.2\right)$, small (SMD = 0.2 to 0.59$)$, moderate $(\mathrm{SMD}=0.6$ to 1.19$)$, large (SMD = 1.20 to 2.00$)$, very large (SMD = 2.00 to 3.99), and extremely large (SMD > 4.00) according to Hopkins et al. [50]; SMD: standardized mean difference.

None of the participants had orthopedic problems affecting the knee, thigh, hip, or lower back in the previous three months the could have impacted the players' habitual movement competency and/or lower extremity ROM profile. Four goalkeepers ( 2 males and 2 females) and 2 male junior IH players were excluded. Goalkeepers were excluded because they show significant physiological differences (body composition, anaerobic power, strength, and flexibility) to field (defense and forward) hockey players [51]. Two junior inline hockey were excluded because these players had been selected to assist in training and did not have the same competitive level. Finally, data from 20 players were analyzed (Table 1).

The measures of hip ROM were conducted at the end of the competition phase of the year 2017. Before participation, the experimental procedures and potential risks of the ROM assessment were fully explained to the participants in verbal and written form, and a written informed consent was obtained. The experimental procedures used in this study were in accordance with the Declaration of Helsinki and ethical approval was obtained from the Ethics and Scientific Committee of the University of Murcia (Spain) [ID: 1702/2017]. 


\subsection{Procedure}

The evaluation session was conducted in the previous technical meeting of the Spanish National Team prior to the participation in the Roller Games World Championship in Nanjing in 2017. All the IH players were asymptomatic in the evaluation session. Both the questionnaire (demographic, sport-related background, training regimen, and previous history of LBP) and hip ROM were conducted the first three days of the technical meeting. Six or seven players were measured each day. Anthropometric traits (weight, height, body mass index, and body fat) and ROMs (hip, knee, and ankle) were assessed by two experienced examiners.

\subsection{Questionnaire}

Before the ROM measurement, the participants completed a questionnaire based on previous studies including information related to sport background (tactical position, current competitive level, dominant lower extremity, sport experience), anthropometric traits (body mass, stature, and body mass index), and training regimen (weekly practice frequency, hours of IH practice per week and day). The LBP-related questions was based on standardized, validated, and internationally accepted Nordic questionnaires to study the prevalence of occupational symptoms [52,53]. The following standard questions from the Nordic questionnaire were included:

- Have you ever experienced LBP?

- Have you ever experienced LBP during the previous seven days?

- How many days during the last 12 months have you had LBP?

- Have you been examined or treated for LBP by a physician, physical therapist, chiropractor, or other health personnel as an outpatient during the previous 12 months?

Low back pain was defined as "pain, ache, or discomfort in the lower back with or without radiation to one or both legs". LBP was considered when IH players had experienced any LBP limiting their performance for a period greater than three days. LBP lasting for 48-72 hours was considered as "delayed onset muscle soreness" [9].

\subsection{ROM-Sport Battery}

Measures of eight passive hip ROMs were taken. The maximum passive hip extension [HE] (iliopsoas, Figure 1A), hip adduction with hip flexed $90^{\circ}$ [HAD-HF] (piriformis, Figure 1B), hip flexion with knee flexed [HF-KF] (gluteus maximus, Figure 1C) and extended [HF-KE] (hamstring, Figure 1D), hip abduction with hip neutral [HAB] (adductors, Figure 1E) and hip flexed 90 [HAB-HF] (monoarticular adductors, 1F), hip internal rotation [HIR] (external rotators, 1G), hip external rotation [HER] (internal rotators, $1 \mathrm{H}$ ), and hip total rotation [HTR] ROMs of the dominant and non-dominant leg were assessed following the methodology previously described (ROM-Sport Battery) [54] (Figure 1). The value of HTR was obtained from the sum of the value of HIR and the value of HER.

These tests were selected based on previous reliability $[55,56]$ and validity $[57,58]$ studies, and also based on the anatomical knowledge and extensive clinical and sport experience $[59,60]$. Furthermore, these tests have been considered appropriate by the American medical organizations $[59,61]$ and included in manuals of Sports Medicine and Science [59,60,62-64]. In addition, studies from our laboratory have reported moderate to high reliability (variability ranging from $4^{\circ}$ to $7^{\circ}$ ) for the procedures employed $[65,66]$. 


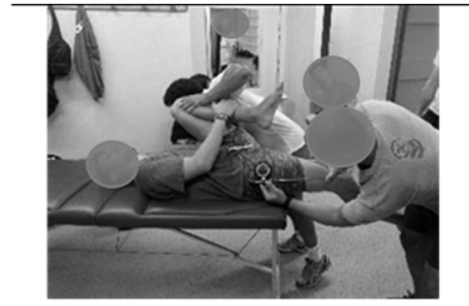

$1 \mathrm{~A}$

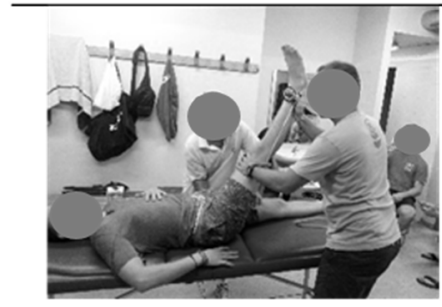

1D

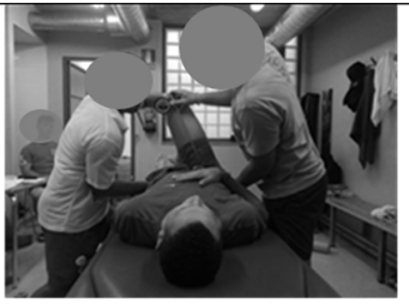

1B

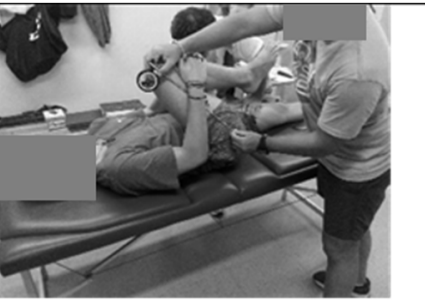

$1 C$

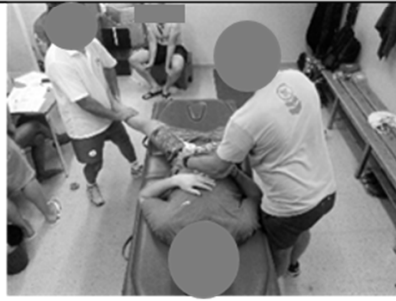

$1 \mathrm{E}$

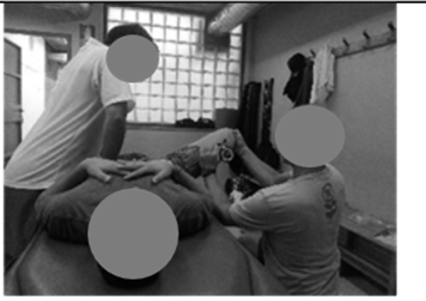

$1 \mathrm{~F}$

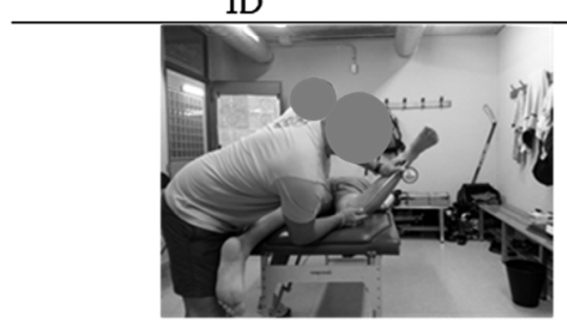

$1 G$

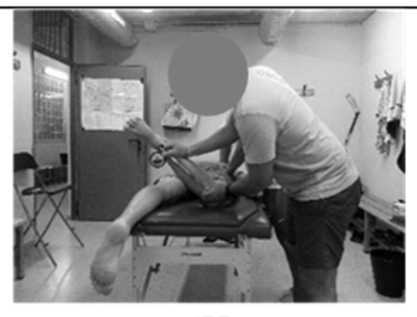

$1 \mathrm{H}$

Figure 1. Lower extremity hip ranges of motion of the ROM-Sport Battery: Hip extension test [HE] (A), hip adduction with hip flexed $90^{\circ}$ test [HAD-HF] (B), hip flexion with knee flexed test [HF-KF] (C), hip flexion with knee extended test [HF-KE] (D), hip abduction with hip neutral test [HAB] (E), hip abduction with hip flexed $90^{\circ}$ test $[\mathrm{HAB}-\mathrm{HF}](\mathbf{F})$, hip internal rotation test [HIR] (G), hip external rotation test [HER] (H); ROM: range of motion.

One familiarization session and one testing session were made. The familiarization session was performed one week before the study. The purpose of the familiarization session was explaining to the players the correct technical execution of the exploratory tests. The dominant leg was defined as the participant's preferred kicking leg [54]. All tests were carried out by the same two experienced examiners (one conducted the tests and the other ensured proper testing position of the participants) under stable environmental conditions. The sport scientists were blinded to the purpose of the study.

Prior to the testing session, all participants performed the dynamic warm-up designed by Taylor et al. [67]. The warm-up lasted approximately 15-20 min. A 3-5-min rest interval between the end of the warm-up and beginning of the ROM assessment was given to the IH players; this was the time needed to get hydration and to dry their sweat before ROMs' assessment [68]. It is important to note that it has been shown that the effects elicited by the dynamic warm-up on the muscle properties lasted more than 5 min [69] and, hence, decreases in ROM values within the 3-5-min rest interval were not expected.

After the warm-up, IH players were asked to perform two repetitions of each ROM test for each leg. The mean score for each test was used in the analyses. The ROM tests were performed in a randomized order. The IH players were examined wearing sports clothes and without shoes. They were allowed to rest for $30 \mathrm{~s}$ between repetitions, legs, and tests. 
Lower extremity hip ranges of motion were measured using an ISOMED Unilevel inclinometer (Portland, Oregon) with an extendable telescopic rod [65]. Before each assessment session, the inclinometer was calibrated to $0^{\circ}$ either with the vertical or horizontal. The angle between the longitudinal axis of the mobilized segment was recorded (following its bisector) with the vertical or the horizontal [65,69]. A metal goniometer with a long arm (Baseline@Stainless) was used to measure the hip abduction movement with a hip neutral and a lumbar support (Lumbosant, Murcia, Spain) to standardize the lumbar curvature [70,71].

The endpoint for each test was determined using at least one of the following criteria: (1) An examiner felt or appreciated some compensation movement that increased the ROM onset of pelvic rotation and/or (2) the IH player felt a strong but tolerable stretch, slightly before the occurrence of pain [65].

\subsection{Statistical Analysis}

Before the statistical analysis, the distribution of raw data sets was checked using the Shapiro-Wilk tests to determine normality of data. The Levene's test was used to assess homogeneity of variance between groups (male vs. female). The results demonstrated that all data had an abnormal distribution.

Descriptive statistics including means and standard deviations were calculated for all variables studied. Data were analyzed using independent sample of the Mann-Whitney $U$ test to examine possible differences in demographic variables and hip ROMs between the male and female groups. In addition, the Wilcoxon test was carried out to assess differences between the values of the dominant and non-dominant limbs (asymmetry). Additionally, Cohen's effect size was calculated for all ROM results. The magnitude of the effect size was classified as previously described by Hopkins et al. [50] as trivial $(<0.2)$, small $(0.2$ to 0.59$)$, moderate ( 0.6 to 1.19$)$, large (1.20 to 2.00$)$, very large (2.00 to 3.99$)$, or extremely large ( $>4.0)$. Asymmetry was considered when the magnitude of the effect size was moderate, which is established as the minimum level of relevant effect with practical application [50] or higher than moderate.

The Mann-Whitney U test was performed to compare the continuous variables (anthropometric characteristics, sport-related background, and training regimen variables, eight hip ROMs, and the eight hip ROMs' asymmetry) between the IH players displaying LBP and those asymptomatic. Additionally, Cohen's effect size was calculated for all ROM results, and the magnitudes of the effect were classified as described above.

The relationship between the independent variables and the dependent variable was examined by backward stepwise binary logistic regression (forward selection [conditional], inclusion probability $p \leq 0.05$, elimination probability $p \leq 0.10$ ) with OR (Odds ratio) analysis was used as in previous studies [33,72,73] for estimating the simultaneous effects of several predictors instead of relative risk estimates [74]. Effect sizes for the OR were defined as follows: Small effect $\mathrm{OR}=1-1.25$, medium effect $\mathrm{OR}=1.25-2$, and large effect $\mathrm{OR} \geq 2$ [75].

To determine whether it was possible to find a clinically relevant cutoff point for ROM that could be used for pointing out individuals at high risk for LBP, receiver operating characteristic (ROC) curves were calculated. The area under the ROC curve represented the probability that a selection based on the risk factor for a randomly chosen positive case would exceed the result for a randomly chosen negative case. The area under the curve could range from 0.5 (no accuracy) to 1.0 (perfect accuracy). If it was found to be statistically significant, it meant that using the risk factor as a determinant was better than guessing. Since the ROC curve plots sensitivity against 1 minus specificity, the coordinates of the curve can be considered possible cutoff points, and the most suitable cutoff can be chosen.

Among the IH players who sustained LBP, Pearson's chi-squared test was used to examine the existence of a relationship between the ROM classification (normal and limited) and LBP. Analysis was performed using the SPSS version 20 software (SPSS Inc, Chicago, IL, USA). For all analyses, significance was accepted at $p<0.05$. Data were presented as means \pm standard deviation. 


\section{Results}

Significant differences in ROM according to sex (Table 2) were observed in HAD-HF $(p$ [statistical difference value] $=0.019, \mathrm{~d}$ [Effect sizes Cohen's $\mathrm{d}]=-1.2297), \operatorname{HER}(p=0.029, \mathrm{~d}=-1.2297)$, HAB-HF $(p=0.005, \mathrm{~d}=-1.4821)$ and HF-KF $(p=0.002, \mathrm{~d}=-1.823)$. ROM asymmetry of the hip was observed in HF-KF ( $p=0.042, \mathrm{~d}=0.724)$ in male IH players and HAB $(p=0.005, \mathrm{~d}=1.176)$ and HTR $(p=0.016, \mathrm{~d}=0.680)$ in female IH players, with the lower values in the non-dominant limb (Table 2).

Table 2. Differences in range of movement according to the sex and asymmetry in Spanish elite inline hockey players $(n=20)$.

\begin{tabular}{|c|c|c|c|c|c|c|c|c|c|c|}
\hline \multirow{2}{*}{ Variables } & \multicolumn{4}{|c|}{ Male $(n=10)$} & \multicolumn{4}{|c|}{ Female $(n=10)$} & \multicolumn{2}{|c|}{ Male Versus Female } \\
\hline & Dom & NDom & $p$-Value & ES (d) & Dom & NDom & $p$-Value & ES (d) & $p$-Value & ES (d) \\
\hline HE (iliopsoas) & $7.0 \pm 5.8$ & $9.80 \pm 7.8$ & 0.132 & $\begin{array}{l}-0.328 \\
\text { Small }\end{array}$ & $8.2 \pm 5.9$ & $10.4 \pm 4.40$ & 0.178 & $\begin{array}{l}-0.441 \\
\text { Small }\end{array}$ & 0.494 & $\begin{array}{c}-0.1632 \\
\text { Trivial }\end{array}$ \\
\hline HAD-HF (piriformis) & $25.0 \pm 3.3$ & $27.60 \pm 5.8$ & 0.128 & $\begin{array}{l}-0.485 \\
\text { Small }\end{array}$ & $31.2 \pm 5.6$ & $32.4 \pm 4.7$ & 0.279 & $\begin{array}{l}-0.220 \\
\text { Small }\end{array}$ & 0.019 & $\begin{array}{l}-1.2297 \\
\text { Large }\end{array}$ \\
\hline HAB (adductors) & $39.2 \pm 3.2$ & $38.60 \pm 3.5$ & 0.560 & $\begin{array}{l}0.333 \\
\text { Small } \\
\end{array}$ & $41.2 \pm 2.9$ & $38.8 \pm 3.2$ & 0.005 & $\begin{array}{c}1.176 \\
\text { Moderate }\end{array}$ & 0.393 & $\begin{array}{c}-0.3791 \\
\text { Small }\end{array}$ \\
\hline HIR (external rotators) & $35.0 \pm 6.6$ & $37.20 \pm 4.6$ & 0.146 & $\begin{array}{l}-0.392 \\
\text { Small }\end{array}$ & $41.8 \pm 6.3$ & $39.2 \pm 4.8$ & 0.090 & $\begin{array}{l}0.392 \\
\text { Small }\end{array}$ & 0.190 & $\begin{array}{c}-0.8381 \\
\text { Moderate }\end{array}$ \\
\hline HER (internal rotators) & $57.6 \pm 10.9$ & $53.20 \pm 8.1$ & 0.068 & $\begin{array}{l}0.441 \\
\text { Small }\end{array}$ & $64.8 \pm 5.3$ & $62.20 \pm 6.9$ & 0.057 & $\begin{array}{l}0.362 \\
\text { Small }\end{array}$ & 0.029 & $\begin{array}{c}-1.0645 \\
\text { Moderate }\end{array}$ \\
\hline $\begin{array}{l}\text { HTR (external and } \\
\text { internal rotators) }\end{array}$ & $92.6 \pm 15.4$ & $90.4 \pm 11.7$ & 0.360 & $\begin{array}{l}0.15 \\
\text { Trivial }\end{array}$ & $106.6 \pm 6.0$ & $101.4 \pm 8.9$ & 0.016 & $\begin{array}{l}\text { Moderate } \\
0.680\end{array}$ & 0.052 & $\begin{array}{l}-1.1757 \\
\text { Moderate }\end{array}$ \\
\hline $\begin{array}{c}\text { HAB-HF } \\
\text { (adductors monoarticular) }\end{array}$ & $64.0 \pm 7.2$ & $65.60 \pm 6.1$ & 0.387 & $\begin{array}{l}-0.153 \\
\text { Small }\end{array}$ & $73.4 \pm 5.8$ & $72.60 \pm 4.8$ & 0.555 & $\begin{array}{l}0.220 \\
\text { Small }\end{array}$ & 0.005 & $\begin{array}{l}-1.4821 \\
\text { Large }\end{array}$ \\
\hline HF-KE (hamstring) & $71.4 \pm 4.2$ & $70.40 \pm 4.1$ & 0.322 & $\begin{array}{l}0.250 \\
\text { Small }\end{array}$ & $74.00 \pm 6.6$ & $74.40 \pm 6.9$ & 0.716 & $\begin{array}{c}0 \\
\text { Trivial }\end{array}$ & 0.315 & $\begin{array}{c}-0.6088 \\
\text { Moderate }\end{array}$ \\
\hline $\begin{array}{c}\text { HF-KF } \\
\text { (gluteus maximus) }\end{array}$ & $133.2 \pm 6.3$ & $\begin{array}{c}129.80 \pm \\
5.5\end{array}$ & 0.042 & $\begin{array}{l}0.724 \\
\text { Moderate }\end{array}$ & $141.8 \pm 6.2$ & $\begin{array}{c}140.20 \pm \\
4.9\end{array}$ & 0.366 & $\begin{array}{l}0.196 \\
\text { Trivial }\end{array}$ & 0.002 & $\begin{array}{l}-1.8239 \\
\text { Large }\end{array}$ \\
\hline $\begin{array}{l}\text { Dom: Dominant sid } \\
\text { with hip flexed } 90^{\circ} \text { t } \\
\text { rotation test [HER]; } \\
\text { hip flexion with kne } \\
\text { mean difference] }< \\
\text { (SMD }=2.00 \text { to } 3.99 \text { ) }\end{array}$ & $\begin{array}{l}\text {; hip abdu } \\
\text { ee flexed te } \\
0.2 \text {, small }\end{array}$ & n-domir & side; & (d): Ef & ct sizes & ted as $t$ & 1 or 1 & ffect (SM) & ID [st & $\begin{array}{l}\text { uction } \\
\text { ternal } \\
\text { F-KE]; } \\
\text { dized } \\
\text { large }\end{array}$ \\
\hline
\end{tabular}

Of the $20 \mathrm{IH}$ players included in this study, $14 \mathrm{IH}$ players experienced LBP at least once during the previous 12 months. Players with history of LBP and asymptomatic ones had similar training volume during the study period. There were statistically significant differences and effect size $(\mathrm{d}>0.6)$ between LBP group and asymptomatic group in HER [LBP group $62.1 \pm 8.2^{\circ}$ vs. asymptomatic group $53.2 \pm 5.5^{\circ}$, $p=0.013, \mathrm{~d}=1.17$ (large effect sizes)] and HTR [LBP group $101.3 \pm 12^{\circ}$ vs. asymptomatic group $89.5 \pm 8.7^{\circ}$, $p=0.032, \mathrm{~d}=1.05$ (moderate effect sizes)]. The group of IH players with LBP had an increased range of $8.9^{\circ}$ and $11.8^{\circ}$ in the HER and HTR, respectively (Table 3 ).

Stepwise logistic regression analysis showed that of all variables described in Table 3 entered into the model (Table 4), only HER showed small predictors of LBP occurrence in the 20 IH players $(\mathrm{OR}=1.174$ [small], 95\% CI [Confidence Interval] $=0.995$ to $1.386, p=0.057)$. In addition, the analysis of the frequencies showed $85.7 \%$ of successful cases in $20 \mathrm{IH}$ players with LBP who were categorized with high HER (high extensibility of internal rotator muscles, cutoff $\geq 56.5^{\circ}$ ), according to the present study. None of the other intrinsic factors imposed a significant relative risk for LBP $(p>0.05)$. 
Table 3. Comparative analysis of studied variables between inline hockey players displaying LBP and asymptomatic players.

\begin{tabular}{|c|c|c|c|c|}
\hline Variables & $\operatorname{LBP}(n=14)$ & Asymptomatic $(n=6)$ & $p$-Value & Effect Sizes Cohen's d \\
\hline Age (years) & $22.71 \pm 3.02$ & $22.0 \pm 2.76$ & 0.402 & $\begin{array}{c}\text { Trivial } \\
(\mathrm{d}=0.24)\end{array}$ \\
\hline Body mass $(\mathrm{kg})$ & $67.11 \pm 8.87$ & $74.57 \pm 9.69$ & 0.091 & $\begin{array}{l}\text { Moderate } \\
(\mathrm{d}=-0.81)\end{array}$ \\
\hline Height $(\mathrm{cm})$ & $1.68 \pm 0.06$ & $1.73 \pm 0.05$ & 0.091 & $\begin{array}{l}\text { Moderate } \\
(\mathrm{d}=-0.87)\end{array}$ \\
\hline $\operatorname{BMI}\left(\mathrm{kg} / \mathrm{m}^{2}\right)$ & $23.83 \pm 2.83$ & $24.87 \pm 2.68$ & 0.444 & $\begin{array}{c}\text { Small } \\
(\mathrm{d}=-0.37)\end{array}$ \\
\hline Years of experience & $13.71 \pm 3.87$ & $13.17 \pm 2.64$ & 0.718 & $\begin{array}{c}\text { Trivial } \\
(\mathrm{d}=0.15)\end{array}$ \\
\hline Months of training per year & $10.36 \pm 0.74$ & $11.17 \pm 0.98$ & 0.109 & $\begin{array}{l}\text { Moderate } \\
(\mathrm{d}=-0.99)\end{array}$ \\
\hline Days of training per week & $2.86 \pm 0.86$ & $2.67 \pm 0.52$ & 0.841 & $\begin{array}{c}\text { Small } \\
(\mathrm{d}=0.24)\end{array}$ \\
\hline Training hours per week & $5.29 \pm 2.13$ & $5.00 \pm 1.90$ & 0.779 & $\begin{array}{l}\text { Trivial } \\
(\mathrm{d}=0.14)\end{array}$ \\
\hline $\begin{array}{l}\text { Training volume } \\
\text { (training hours last } 12 \text { month) }\end{array}$ & $201.5 \pm 83.3$ & $176.0 \pm 62.2$ & 0.693 & $\begin{array}{c}\text { Small } \\
(\mathrm{d}=0.32)\end{array}$ \\
\hline HE (iliopsoas) & $8.1 \pm 4.5^{\circ}$ & $10.7 \pm 7.3^{\circ}$ & 0.431 & $\begin{array}{c}\text { Small } \\
(\mathrm{d}=-0.47)\end{array}$ \\
\hline HAD-HF (piriformis) & $30.1 \pm 5.4^{\circ}$ & $26.5 \pm 4.1^{\circ}$ & 0.136 & $\begin{array}{l}\text { Moderate } \\
(\mathrm{d}=0.70)\end{array}$ \\
\hline HAB (adductors) & $39.9 \pm 3.0^{\circ}$ & $38.5 \pm 2.5^{\circ}$ & 0.406 & $\begin{array}{c}\text { Small } \\
(\mathrm{d}=0.48)\end{array}$ \\
\hline HIR (external rotators) & $39.1 \pm 5.7^{\circ}$ & $36.3 \pm 5.2^{\circ}$ & 0.341 & $\begin{array}{c}\text { Small } \\
(\mathrm{d}=0.5)\end{array}$ \\
\hline HER (internal rotators) & $62.1 \pm 8.2^{\circ}$ & $53.2 \pm 5.5^{\circ}$ & $0.013 *$ & $\begin{array}{c}\text { Large } \\
(\mathrm{d}=1.17)\end{array}$ \\
\hline $\begin{array}{l}\text { HTR (external and } \\
\text { internal rotators) }\end{array}$ & $101.3 \pm 12.0^{\circ}$ & $89.5 \pm 8.7^{\circ}$ & $0.032 *$ & $\begin{array}{l}\text { Moderate } \\
(\mathrm{d}=1.05)\end{array}$ \\
\hline $\begin{array}{c}\text { HAB-HF } \\
\text { (monoarticular adductors) }\end{array}$ & $70.4 \pm 6.4^{\circ}$ & $65.5 \pm 7.1^{\circ}$ & 0.186 & $\begin{array}{l}\text { Moderate } \\
(\mathrm{d}=0.74)\end{array}$ \\
\hline HF-KE (hamstring) & $72.1 \pm 5.4^{\circ}$ & $73.7 \pm 6.2^{\circ}$ & 0.534 & $\begin{array}{c}\text { Small } \\
(\mathrm{d}=-0.28)\end{array}$ \\
\hline HF-KF (gluteus maximus) & $137.3 \pm 7.2^{\circ}$ & $133.8 \pm 6.6^{\circ}$ & 0.301 & $\begin{array}{c}\text { Small } \\
(\mathrm{d}=0.49)\end{array}$ \\
\hline
\end{tabular}

Data are expressed as mean \pm standard deviation; LBP: Lower back pain; Hip extension test [HE]; hip adduction with hip flexed $90^{\circ}$ test [HAD-HF]; hip abduction with hip neutral test [HAB]; hip internal rotation test [HIR]; hip external rotation test [HER]; hip abduction with hip flexed $90^{\circ}$ test [HAB-HF]; hip flexion with knee extended test [HF-KE]; hip flexion with knee flexed test [HF-KF]; * significant at $p \leq 0.05$ (nonparametric Mann-Whitney U test). Effect sizes were was interpreted as trivial or no effect (SMD [standardized mean difference] $<0.2$ ), small (SMD = 0.2 to 0.59), moderate $(\mathrm{SMD}=0.6$ to 1.19$)$, large $(\mathrm{SMD}=1.20$ to 2.00$)$, very large $(\mathrm{SMD}=2.00$ to 3.99$)$, and extremely large $(\mathrm{SMD}>4.00)[50]$.

Two movements showed a good accuracy of the predictive model for LBP [76]. The area under the ROC curves for HER and HTR was 0.857 and 0.810, respectively (Figures 2 and 3), being statistically significant (HER [ $p=0.013$, standard error: $0.087,95 \%$ confidence interval: 0.687 to 1.000$]$, HTR [ $p=0.032$, standard error: $0.097,95 \%$ confidence interval: 0.619 to 1.000$]$ ). Using the coordinates of the curves, 
the angles of HER and HTR that most accurately identified individuals at risk for LBP were $56.5^{\circ}$ (sensibility 0.857 and 0.333 specificity) and $93^{\circ}$ (sensibility 0.857 and 0.333 specificity), respectively.

Table 4. Frequencies and logistic regression results: Intrinsic risk factors for lower back pain in the elite inline hockey players.

\begin{tabular}{|c|c|c|c|c|c|c|}
\hline Variable & \multicolumn{2}{|c|}{ Frequencies (\%) } & \multicolumn{4}{|c|}{ Statistics } \\
\hline LBP (14 vs. 6) & $\geq 56.5^{\circ}$ & $<56.5^{\circ}$ & OR & SE & $95 \% \mathrm{CI}$ & $p$-Value \\
\hline \multirow{2}{*}{ HER } & Asymptomatic 33.3 & 66.7 & \multirow{2}{*}{1.174} & \multirow{2}{*}{0.085} & \multirow{2}{*}{0.995 to 1.386} & \multirow{2}{*}{0.057} \\
\hline & LBP & 14.3 & & & & \\
\hline
\end{tabular}

HIR: hip internal rotation test; tightness (high risk) establish at $56.5^{\circ}$ in the present study; LBP: Lower back pain; OR: Odds ratio (relative risk); $\mathrm{OR}>1$ : Increased odds of shoulder pain; small effect $\mathrm{OR}=1-1.25$, medium effect $\mathrm{OR}=1.25-2$ and large effect $\mathrm{OR} \geq 2$ [75]; SE: Standard error; CI: Confidence interval.

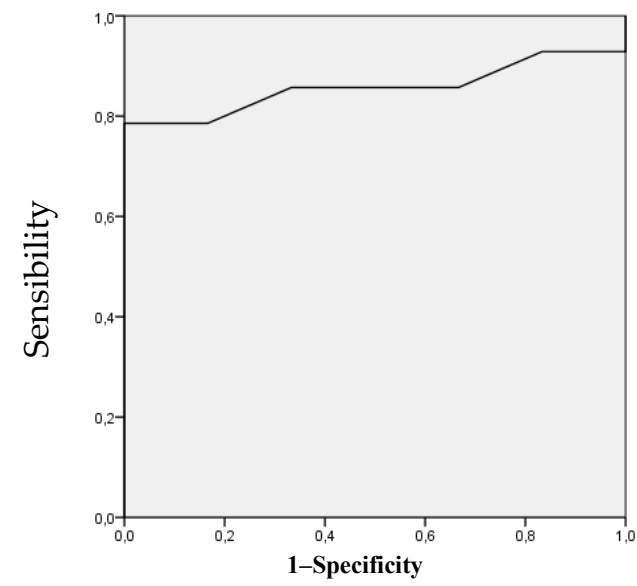

Figure 2. Receiver operating characteristic curve analysis for the hip external rotation ROM as a risk factor for lower back pain. The area under the curve is $0.857(p=0.013)$; the coordinates represent possible cutoff point in hip external rotation range of movement (the optimal cutoff point was $56.5^{\circ}$ ).

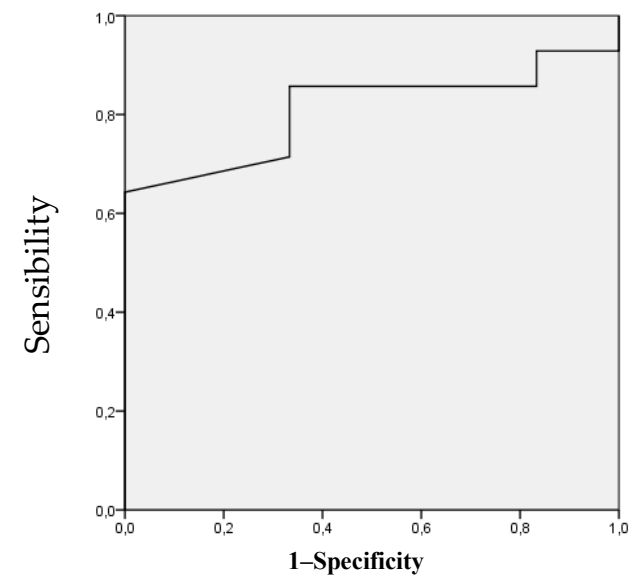

Figure 3. Receiver operating characteristic curve analysis for the hip total rotation ROM as a risk factor for lower back pain. The area under the curve is $0.810(p=0.032)$; the coordinates represent possible cutoff point in hip total rotation range of movement (the optimal cutoff point was $93^{\circ}$ ). 
Finally, the Pearson's chi-squared test showed significant differences between the proportions of IH players with high and normal ROM for HER and HTR, and players with LBP and asymptomatic ( $p=0.019$, $95 \%$ confidence interval 1.248 to 115.362). IH players with HER $\geq 56.5^{\circ}$ and HTR $\geq 93^{\circ}$ have 12 times more risk of developing LBP than IH players with HER $<56.5^{\circ}$ and HTR $<93^{\circ}$.

\section{Discussion}

\subsection{Tightness as an Intrinsic Risk Factor for the Development of Low Back Pain [LBP]}

The review of the literature shows that age, body mass index, sex, body mass, height, years of experience as an IH player, training hours per week, competitive level, long sticks, ROM, or asymmetry are suggested as possible risk factors for LBP [21,43,45,77-80]. In the current study, we found significant differences between both groups of players (LBP vs. asymptomatic) with respect to the HER ( $p=0.013$, $\mathrm{d}=1.17$ [large effect sizes]) and HTR $(p=0.032, \mathrm{~d}=1.05$ [large effect sizes]) in the descriptive analysis. Interestingly, the IH players with LBP had higher values in both ROMs than the asymptomatic ones. In addition, this result was confirmed by the regression model, which showed that the only predisposing factor for the development of LBP in IH players was a HER higher than $56.5^{\circ}$. This unexpected result is the main finding of our study.

Interestingly, these results differed from those reported previously, where the association between the limited hip ROM and LBP has been investigated in several sports. Van Dillen, Bloom, Gombatto, and Susco [20] showed that racket sports and golf athletes with a chronic or recurrent LBP history displayed significantly less HIR (LBP $27.7^{\circ}$ vs. asymptomatic $30.4^{\circ}$ ) and HER (LBP $26.5^{\circ}$ vs. asymptomatic $30.8^{\circ}$ ) than those without LBP history. In this sense, two studies including professional golfers and tennis players conducted by Vad et al. $[9,10]$ also found a deficit in HIR in those athletes displaying LBP compared with asymptomatic players $\left(11.8^{\circ}\right.$ vs. $16.9^{\circ}, 16.1^{\circ}$ vs. $\left.24.2^{\circ}\right)$. This observation has been also made in amateur golf athletes $\left(21.1^{\circ}\right.$ vs. $\left.31.1^{\circ}\right)$ in active and passive hip rotation tests [21]. Similar results have been reported in judo [22], showing the athletes with LBP have limited active HIR $\left(39.5^{\circ}\right.$ vs. $\left.46.7^{\circ}\right)$ on the dominant side and HTR $\left(97.6^{\circ}\right.$ vs. $105.1^{\circ}$ ) compared to those without LBP and reduced passive HIR (dominant limb, $41.9^{\circ}$ vs. $46.1^{\circ}$, non-dominant limb, $37.1^{\circ}$ vs. $\left.47.3^{\circ}\right)$ in both sides and HTR $\left(98.5^{\circ}\right.$ vs. $\left.105^{\circ}\right)$. The results observed in athletes with LBP in these studies may be explained by the high training loads and repeated technical movements used in training and competition during the sports' season, when the recovery measures and recovery time are not sufficient $[43,81,82]$. This situation produces musculoskeletal adaptations such as muscle tightness, limited ROM, and muscle imbalance that predispose to LBP $[43,83,84]$.

The differences between our study and those reported previously may be explained by the sport-specific movements performed by athletes. In this sense, a large number of studies have confirmed that flexibility is specific to each sport $[85,86]$ and tactical position $[87,88]$ and may also depend on the competitive level of the players $[89,90]$. Skating is a unique pattern of movement in sport and the most important basic skill in $\mathrm{IH}$. Inline skating is characterized by the continuous movement of hip internal and external rotation with the players turning, stopping, crossing over, skating from start propulsion, or transitioning from start to maximum speed [39]. During the sliding phase, when the skate is set on the ground and players are progressively loading all their weight onto their pushing leg, progressive flexion of the hip and knee as well as ankle dorsi-flexion are performed. The push-off phase starts in the middle of the sliding phase, while leaning on the pushing leg, and involves hip external rotation, abduction, and extension, knee extension, and ankle plantar flexion. The later recovery phase of the pushing leg involves hip adduction, flexion, and internal rotation, knee flexion, and ankle dorsiflexion $[38,39,91]$. These technical features of skating result in very wide hip ROMs in order to achieved maximum performance. The increment of hip flexibility, especially in the iliopsoas, adductors, hamstring, gluteus maximus, or piriformis, improve speed, power, and efficiency of skating $[39,92,93]$. As a consequence, the hip rotation ROMs in IH players 
(HER 53.2 $2^{\circ}$ and HIR 36.3 ${ }^{\circ}$ ) are much higher than those reported in tennis [10-28], racket sports [20], judo [22], and golf athletes $[9,20]$.

However, extremely wide HER and HIR, as observed in our study, may cause compensatory movements in the pelvis and the lumbar region [94]. Those players showing LBP in this study probably had altered coordination of hip and lumbopelvic region that resulted in an increase in lumbopelvic-region movements and produced LBP symptoms. It has been already described that lumbopelvic rotation, pelvis anteversion, and the increased lumbar curvature generate lumbar overload and stress and, consequently, LBP symptoms [30,94]. Another important factor affecting the incidence of LBP is the relation between HER and HIR. Usually, the difference between HER and HIR ranges from $5^{\circ}$ to $10^{\circ}$, HER being higher than HIR $[59,61,63,64]$. However, when the difference is higher than $10^{\circ}$ (hip pattern III [30]), as occurred in the present study with an average difference between HER and HIR of $23^{\circ}$ in LBP players and $16.9^{\circ}$ in the asymptomatic ones, there is a higher predisposition to low back pain [30-95]. Cibulka et al. [24,95] identified a specific pattern of passive hip rotation motion in people with LBP, which had significantly greater HER than HIR bilaterally, whereas those with evidence of sacroiliac joint dysfunction had significantly greater HER than HIR unilaterally. Therefore, all these facts, which related to the skating technique and the physical demands of IH players, can explain why the high values of HER and HTR found in the present study are related to the incidence of LBP.

\subsection{Asymmetry as an Intrinsic Risk Factors for the Development of Low Back Pain [LBP]}

The ROM asymmetry is also considered an important risk factor for sport injury. In the current study, hip ROM asymmetry was observed in HF-KF, HER, HTR, and HAB, with the lower values in the non-dominant limb. However, the differences in asymmetry magnitude were not significant between the LBP and the asymptomatic group. The results of LBP predictive model revealed that asymmetry was not a predicting factor for LBP in IH players. This sport shows a highly symmetrical performance during skating [96]. In the small proportion of $\mathrm{IH}$ players showing asymmetry, it is possible that technical demands result in a higher overload of the non-dominant lower limb, producing a decreased ROM in some movements. Our results related to asymmetry cannot be compared with previous reports about hockey $[4,5,43,45,46,51]$, because asymmetry was not analyzed in those studies.

On the contrary, in other sport disciplines asymmetry has been related to LBP performing descriptive analysis between the right and left extremity. Thus, Sadeghisani et al. [78] described that asymmetry in the HIR and HTR were common findings in patients and athletes with LBP. Van Dillen, Bloom, Gombatto, and Susco [20] reported that athletes of a rotation-related sport with a history of chronic or recurrent LBP displayed more asymmetry in hip rotation (HER and HIR) compared to those without LBP symptoms. In professional golfers [9] and tennis [10] players, Vad et al. found greater asymmetry of HIR in players with LBP. Almeida, de Souza, Sano, Saccol, and Cohen [22] observed that judo athletes with LBP demonstrated hip rotation asymmetry between the dominant and non-dominant side. The different results of these studies and ours could be due to the definition of asymmetry and the statistical analysis used. Also, the dominant and non-dominant extremities should be considered in the analysis due to the flexibility specificity in the sport.

\subsection{Practical Considerations}

These findings suggest that great attention should be given to the regular assessment of the flexibility during screening of athletes to individually identify players and high risk of LBP by high HER values. Athletes with greater HER often have weakness of the hip internal rotator muscles (tensor fasciae latae and gluteus medius and minimus) $[63,64,97]$. Hip muscle strengthening exercises are a common intervention to prevent LBP [98]. Stretching and joint mobilization techniques are also commonly used to restore 
optimal hip ROM in cases of muscle and capsular tightness. In this sense, the IH players with HER and HTR ROM higher than $56.5^{\circ}$ and $93^{\circ}$ should follow a mixed exercise program (back stretching, hip stretching, core/gluteus strength, and muscle relaxation exercises) to reduce the risk of recurrent LBP in the future $[44,99]$. One specific aim of this strength/flexibility program should be the balance side-to-side and internal-to-external rotators. Another objective should be the training of the movement quality of the technical skills, especially the coordination of the hip and lumbopelvic region in order to avoid repetition of compensatory movements and the subsequent LBP. A future prospective study with a larger sample would allow studying more variables (i.e., hip, strength, muscle imbalance, dynamic postural control, core stability, training load, etc.) as potential injury risk factors. In addition, the use of machine learning techniques may help to find the best model for predicting LBP with a greater number of risk factors for LBP in IH players.

\section{Conclusions}

The present study demonstrated that HER and HTR are associated with LBP in elite inline hockey players. The cutoff points with the greatest discriminatory power for prognostic screening were those obtained from HER $\left(56.5^{\circ}\right)$ and $\operatorname{HTR}\left(93^{\circ}\right)$.

Inline hockey players display higher ROM values than other rotation-related sports such as judo, golf, or tennis. A hip pattern III predominates in IH players, being the difference between HER and HIR higher than reported for the general population and athletes from other disciplines.

Author Contributions: All authors have read and agree to the published version of the manuscript. Conceptualization, A.C., R.I., F.S.-M., P.S.d.B. and V.J.M.-A.; formal analysis, A.C., R.I., F.S.-M., P.S.d.B. and V.J.M.-A., funding acquisition, A.C., F.S.-M. and P.S.d.B.; investigation, A.C., P.S.d.B., R.I. and V.J.M.-A.; methodology, A.C., F.S.-M. and P.S.B.; project administration, A.C. and P.S.d.B.; resources, P.S.d.B., A.C., F.S.-M., R.I. and V.J.M.-A.; supervision, A.C., V.J.M-A. and P.S.d.B.; writing-original draft, A.C., P.S.d.B., F.S.-M., R.I. and V.J.M.-A.; writing-review and editing, P.S.d.B., A.C., F.S.-M. and V.J.M.-A.

Funding: This study was carried out during the research stay at the Facoltà di Scienze Motorie of Università degli Studi di Urbino "Carlo Bo" from 25 June 2018 to 2 July 2018 (A.C. and P.S.B.) and 29 October 2018 to 3 February 2019 (A.C.) funded by Erasmus Teaching. This research was part of the project entitled "Estudio del riesgo de lesión en jóvenes deportistas a través de redes de inteligencia artificial (Study of injury risk in young athletes through artificial intelligence networks)", funded by the Spanish Ministry of Science and Innovation (DEP2017-88775-P), the State Research Agency (AEI), and the European Regional Development Fund (ERDF).

Conflicts of Interest: The authors declare no conflict of interest. The funders had no role in the design of the study; in the collection, analyses, or interpretation of data; in the writing of the manuscript, or in the decision to publish the results.

\section{References}

1. Real Federación Española de Patinaje. Available online: https://fep.es/website/index.asp?modalidad=5 (accessed on 4 April 2020).

2. Consejo Superior de Deportes. Available online: https://www.csd.gob.es/es (accessed on 18 April 2020).

3. Moreno-Alcaraz, V.; Cejudo, A.; Sainz de Baranda, P. Injury Types and Frequency in Spanish Inline Hockey Players. Phys. Ther. Sport 2020, 42, 91-99. [CrossRef] [PubMed]

4. Hutchinson, M.; Milhouse, C.; Gapski, M. Comparison of Injury Patterns in Elite Hockey Players Using Ice versus In-Line Skates. Med. Sci. Sports Exerc. 1988, 30, 1371-1373. [CrossRef]

5. Varlotta, G.; Lager, S.; Nicholas, S.; Browne, M.; Schlifstein, T. Professional Roller Hockey Injuries. Clin. J. Sport Med. 2000, 10, 29-33. [CrossRef]

6. US Consumer Product Safety Commission. NEISS: National Electronic Injury Surveillance System; US Consumer Product Safety Commission, Ed.; US Consumer Product Safety Commission: Bethesda, MD, USA, 1997.

7. Coplan, J. Ballet Dancer's Turnout and Its Relationship to Self-Reported Injury. J. Orthop. Sports Phys. Ther. 2002, 32, 579-584. [CrossRef] [PubMed] 
8. Grimshaw, P.; Burden, A. Case Report: Reduction of Low Back Pain in a Professional Golfer. Med. Sci. Sports Exerc. 2000, 32, 1667-1673. [CrossRef]

9. Vad, V.; Bhat, A.; Basrai, D.; Gebeh, A.; Aspergren, D.; Andrews, J. Low Back Pain in Professional Golfers: The Role of Associated Hip and Low Back Range-of-Motion Deficits. Am. J. Sports Med. 2004, 32, $494-497$. [CrossRef]

10. Vad, V.; Gebeh, A.; Dines, D.; Altchek, D.; Norris, B. Hip and Shoulder Internal Rotation Range of Motion Deficits in Professional Tennis Players. J. Sci. Med. Sport 2003, 6, 71-75. [CrossRef]

11. Reiman, M.; Weisbach, P.; Glynn, P. The Hip's Influence on Low Back Pain: A Distal Link to a Proximal Problem. J. Sport Rehabil. 2009, 18, 24-32. [CrossRef]

12. Jonasson, P.; Halldin, K.; Karlsson, J.; Thoreson, O.; Hvannberg, J.; Swärd, L.; Baranto, A. Prevalence of Joint-Related Pain in the Extremities and Spine in Five Groups of Top Athletes. Knee Surg. Sports Traumatol. Arthrosc. 2011, 19, 1540-1546. [CrossRef]

13. Burns, S.; Mintken, P.; Austin, G. Clinical Decision Making in a Patient with Secondary Hip-Spine Syndrome Use of Thoracic Manipulation in Individuals with Cervicogenic Headache View Project Survey of Physical Therapists Regarding Practice Patterns around LBP and Hip View Project. Physiother. Theory Pract. 2011, $27,384-397$. [CrossRef]

14. Kibler, W.; McQueen, C. Fitness Evaluations and Fitness Findings in Competitive Junior Tennis Players. Clin. Sports Med. 1988, 7, 403-416. [PubMed]

15. Ekstrand, J.; Wiktorsson, M.; Oberg, B.; Gillquist, J. Lower Extremity Goniometric Measurements: A Study to Determine Their Reliability. Arch. Phys. Med. Rehabil. 1982, 63, 171-175. [PubMed]

16. Karen, D.; Green, D.; Jensen, G.; Savinar, E. A Comparison of Muscular Tightness in Runners and Nonrunners and the Relation of Muscular Tightness to Low Back Pain in Runners. J. Orthop. Sports Phys. Ther. 1985, 6, 315-323. [CrossRef] [PubMed]

17. Winters, M.; Blake, C.; Trost, J. Passive versus Active Stretching of Hip Flexor Muscles in Subjects with Limited Hip Extension: A Randomized Clinical Trial. Phys. Ther. 2004, 84, 800-807. [CrossRef] [PubMed]

18. Harvey, J.; Tanner, S. Low Back Pain in Young Athletes. A Practical Approach. Sports Med. 1991, 12, 394-406. [CrossRef]

19. Kolber, M.; Fiebert, I. Addressing Flexibility of the Rectus Femoris in the Athlete with Low Back Pain. Strength Cond. J. 2005, 27, 66-73. [CrossRef]

20. Van Dillen, L.; Bloom, N.; Gombatto, S.; Susco, T. Hip Rotation Range of Motion in People with and without Low Back Pain Who Participate in Rotation-Related Sports. Phys. Ther. Sport 2008, 9, 72-81. [CrossRef]

21. Murray, E.; Birley, E.; Twycross-Lewis, R.; Morrissey, D. The Relationship between Hip Rotation Range of Movement and Low Back Pain Prevalence in Amateur Golfers: An Observational Study. Phys. Ther. Sport 2009, 10, 131-135. [CrossRef]

22. Almeida, G.; de Souza, V.; Sano, S.; Saccol, M.; Cohen, M. Comparison of Hip Rotation Range of Motion in Judo Athletes with and without History of Low Back Pain. Man. Ther. 2012, 17, 231-235. [CrossRef]

23. Chesworth, B. A Comparison of Hip Mobility in Patients with Nonspecific Low Back Pain. Physiother. Can. 1994, $46,267-274$.

24. Cibulka, M.; Sinacore, D.; Cromer, G.; Delitto, A. Unilateral Hip Rotation Range of Motion Asymmetry in Patients with Sacroiliac Joint Regional Pain. Spine 1998, 23, 1009-1015. [CrossRef] [PubMed]

25. Fairbank, J.; Pynsent, P.; Van, J. Influence of Anthropometric Factors and Joint Laxity in the Incidence of Adolescent Back Pain. Spine 1984, 9, 461-464. [CrossRef] [PubMed]

26. Mellin, G. Decreased Joint and Spinal Mobility Associated with Low Back Pain in Young Adults. J. Spinal Disord. 1990, 3, 238-243. [CrossRef]

27. Giles, L.; Taylor, J. Low-Back Pain Associated with Leg Length Inequality. Spine 1981, 6, 510-521. [CrossRef]

28. Moreno-Pérez, V.; López-Valenciano, A.; Ayala, F.; Fernandez-Fernandez, J.; Vera-Garcia, F. Comparison of Hip Extension and Rotation Ranges of Motion in Young Elite Tennis Players with and without History of Low Back Pain. J. Back Musculoskelet. Rehabil. 2019, 32, 629-638. [CrossRef] [PubMed] 
29. Hjelm, N.; Werner, S.; Renstrom, P. Injury Risk Factors in Junior Tennis Players: A Prospective 2-Year Study. Scand. J. Med. Sci. Sports 2012, 22, 40-48. [CrossRef]

30. Ellison, J.; Rose, S.; Sahrmann, S. Patterns of Hip Rotation Range of Motion: A Comparison between Healthy Subjects and Patients with Low Back Pain. Phys. Ther. 1990, 70, 537-541. [CrossRef]

31. Emery, C.; Meeuwisse, W. Risk Factors for Groin Injuries in Hockey. Med. Sci. Sports Exerc. 2001, 33, $1423-1433$. [CrossRef]

32. Witvrouw, E.; Bellemans, J.; Lysens, R.; Danneels, L.; Cambier, D. Intrinsic Risk Factors for the Development of Patellar Tendinitis in an Athletic Population. Am. J. Sports Med. 2001, 29, 190-195. [CrossRef]

33. Okamura, S.; Wada, N.; Tazawa, M.; Sohmiya, M.; Ibe, Y.; Shimizu, T.; Usuda, S.; Shirakura, K. Injuries and Disorders among Young Ice Skaters: Relationship with Generalized Joint Laxity and Tightness. Open Access J. Sports Med. 2014, 5, 191. [CrossRef]

34. Backman, L.; Danielson, P. Low Range of Ankle Dorsiflexion Predisposes for Patellar Tendinopathy in Junior Elite Basketball Players: A 1-Year Prospective Study. Am. J. Sports Med. 2011, 39, 2626-2633. [CrossRef] [PubMed]

35. Tak, I.; Engelaar, L.; Gouttebarge, V.; Barendrecht, M.; Van den Heuvel, S.; Kerkhoffs, G.; Langhout, R.; Stubbe, J.; Weie, A. Is Lower Hip Range of Motion a Risk Factor for Groin Pain in Athletes? A Systematic Review with Clinical Applications. Br. J. Sports Med. 2017, 51, 1611-1621. [CrossRef] [PubMed]

36. Malliaras, P.; Cook, J.; Kent, P. Reduced Ankle Dorsiflexion Range May Increase the Risk of Patellar Tendon Injury among Volleyball Players. J. Sci. Med. Sport 2006, 9, 304-309. [CrossRef] [PubMed]

37. Cejudo, A.; Sainz De Baranda, P.; Ayala, F.; Santonja, F. Perfil de Flexibilidad de La Extremidad Inferior En Jugadores Senior de Balonmano. Cuad. Psicol. del Deport. 2014, 14, 111-120. [CrossRef]

38. Marino, G. Selected Mechanical Factors Associated with Acceleration in Ice Skating. Res. Q. Exerc. Sport 1983, 54, 234-238. [CrossRef]

39. Pearsall, D.; Turcotte, R.; Murphy, S. Biomechanics of Ice Hockey. Exerc. Sport Sci. 2000, 43, 675-692.

40. Shell, J.; Robbins, S.; Dixon, P.; Renaud, P.; Turcotte, R.; Wu, T.; Pearsall, D. Skating Start Propulsion: Three-Dimensional Kinematic Analysis of Elite Male and Female Ice Hockey Players. Sports Biomech. 2017, 16, 313-324. [CrossRef]

41. Devan, M.; Pescatello, L.; Faghri, P.; Anderson, J. A Prospective Study of Overuse Knee Injuries among Female Athletes with Muscle Imbalances and Structural Abnormalities. J. Athl. Train. 2004, 39, 263-267.

42. Fett, D.; Trompeter, K.; Platen, P. Back Pain in Elite Sports: A Cross-Sectional Study on 1114 Athletes. PLoS ONE 2017, 12, e0180130. [CrossRef]

43. Kawałek, K.; Garsztka, T. An Analysys of Muscle Balance in Professional Field Hockey Players. Trends Sport Sci. 2013, 4, 181-187.

44. Van Hilst, J.; Hilgersom, N.; Kuilman, M.; Paul, P.; Kuijer, F.M.; Frings-Dresen, M. Low Back Pain in Young Elite Field Hockey Players, Football Players and Speed Skaters: Prevalence and Risk Factors. J. Back Musculoskelet. Rehabil. 2015, 28, 67-73. [CrossRef] [PubMed]

45. Wilcox, C.; Osgood, C.; White, H.; Vince, R. Investigating Strength and Range of Motion of the Hip Complex in Ice Hockey. J. Sport Rehabil. 2015, 24, 300-306. [CrossRef] [PubMed]

46. Tyler, T.; Nicholas, S.; Campbell, R.; Mchugh, M. The Association of Hip Strength and Flexibility With the Incidence of Adductor Muscle Strains in Professional Ice Hockey Players. Am. J. Sports Med. 2001, 29, $124-128$. [CrossRef] [PubMed]

47. Wojtys, E.; Ashton-Miller, J.; Huston, L.; Moga, P. The Association between Athletic Training Time and the Sagittal Curvature of the Immature Spine. Am. J. Sports Med. 2000, 28, 490-498. [CrossRef]

48. Sainz de Baranda, P.; Santonja-Medina, F.; Rodríguez-Iniesta, M. Tiempo de Entrenamiento y Plano Sagital Del Raquis En Gimnastas de Trampolín. Rev. Int. Med. y Ciencias la Act. Física y el Deport. 2010, 10, 521-536.

49. Sanz-Mengibar, J.; Sainz de Baranda, P.; Santonja-Medina, F. Training Intensity and Sagittal Curvature of the Spine in Male and Female Artistic Gymnasts. J. Sports Med. Phys. Fitness 2018, 58, 465-471. [CrossRef]

50. Hopkins, W.; Marshall, S.; Batterham, A.; Hanin, J. Progressive Statistics for Studies in Sports Medicine and Exercise Science. Med. Sci. Sports Exerc. 2009, 41, 3-12. [CrossRef] 
51. Quinney, H.; Dewart, R.; Game, A.; Snydmiller, G.; Warburton, D.; Bell, G. A 26 Year Physiological Description of a National Hockey League Team. Appl. Physiol. Nutr. Metab. 2008, 33, 753-760. [CrossRef]

52. Kuorinka, I.; Jonsson, B.; Kilbom, A.; Vinterberg, H.; Biering-Sørensen, F.; Andersson, G.; Jørgensen, K. Standardised Nordic Questionnaires for the Analysis of Musculoskeletal Symptoms. Appl. Ergon. 1987, 18, 233-237. [CrossRef]

53. Foss, I.; Holme, I.; Bahr, R. The Prevalence of Low Back Pain Among Former Elite Cross-Country Skiers, Rowers, Orienteerers, and Nonathletes A 10-Year Cohort Study. Am. J. Sports Med. 2012, 40, 2610-2616. [CrossRef]

54. Cejudo, A.; Robles-Palazón, F.; Sainz de Baranda, P. Asimetrías de Flexibilidad En Jugadores de Fútbol Sala. Rev. Pedagógica ADAL 2017, 34, 31-38.

55. Fourchet, F.; Materne, O.; Horobeanu, C.; Hudacek, T.; Buchheit, M. Reliability of a Novel Procedure to Monitor the Flexibility of Lower Limb Muscle Groups in Highly-Trained Adolescent Athletes. Phys. Ther. Sport 2013, 14, 28-34. [CrossRef]

56. Nussbaumer, S.; Leunig, M.; Glatthorn, J.; Stauffacher, S.; Gerber, H.; Maffiuletti, N. Validity and Test-Retest Reliability of Manual Goniometers for Measuring Passive Hip Range of Motion in Femoroacetabular Impingement Patients. BMC Musculoskelet. Disord. 2010, 11, 194. [CrossRef] [PubMed]

57. Gogia, P.; Braatz, J.; Rose, S.; Norton, B. Reliability and Validity of Goniometric Measurements at the Knee. Phys. Ther. 1987, 67, 192-195. [CrossRef] [PubMed]

58. Enwemeka, C. Radiographic Verification of Knee Goniometry. Scand. J. Rehabil. Med. 1986, 18, 47-49. [PubMed]

59. Gerhardt, J.; Cocchiarella, L.; Lea, R. The Practical Guide to Range of Motion Assessment; American Medical Association: Chicago, IL, USA, 2002.

60. Norkin, C.; White, D. Measurement of Joint Motion: A Guide To Goniometry; FA Davis: Philadelphia, PA, USA, 2016.

61. Surgeons American Academy of Orthopaedic. Joint Motion: Method of Measuring and Recording; Churchill Livingstone: Chicago, IL, USA, 1965.

62. Magee, D. Orthopedic Physical Assessment; Elsevier Health Sciences: Philadelphia, PA, USA, 2013.

63. Palmer, M.; Epler, M. Fundamentos de Las Técnicas de Evaluación Musculoesquelética; Paidotribo: Barcelona, Spain, 2002.

64. Clarkson, H. Proceso Evaluativo Musculoesquelético: Amplitud Del Movimiento Articular y Test Manual de Fuerza Muscular; Paidotribo: Barcelona, Spain, 2003.

65. Cejudo, A.; Sainz de Baranda, P.; Ayala, F.; Santonja, F. Test-Retest Reliability of Seven Common Clinical Tests for Assessing Lower Extremity Muscle Flexibility in Futsal and Handball Players. Phys. Ther. Sport 2015, 16, $107-113$. [CrossRef]

66. Cejudo, A.; Ayala, F.; Sainz de Baranda, P.; Santonja, F. Reliability of Two Methods of Clinical Examination of the Flexibility of the Hip Adductor Muscles. Int. J. Sports Phys. Ther. 2015, 10, 976-983.

67. Taylor, K.L.; Sheppard, J.M.; Lee, H.; Plummer, N. Negative Effect of Static Stretching Restored When Combined with a Sport Specific Warm-up Component. J. Sci. Med. Sport 2009. [CrossRef]

68. Ayala, F.; Moreno-Perez, V.; Vera-Garcia, F.; Moya, M.; Sanz-Rivas, D.; Fernandez-Fernandez, J. Acute and Time-Course Effects of Traditional and Dynamic Warm-up Routines in Young Elite Junior Tennis Players. PLoS ONE 2016, 11, e0152790. [CrossRef]

69. Cejudo, A.; Sainz De Baranda, P.; Ayala, F.; Santonja, F. A Simplified Version of the Weight-Bearing Ankle Lunge Test: Description and Test-Retest Reliability. Man. Ther. 2014, 19, 355-359. [CrossRef]

70. Santonja, F.; Ferrer, V.; Martínez, I. Exploración Clínica Del Síndrome de Isquiosurales Cortos. Selección 1995, 4, 81-91.

71. Santonja-Medina, F.; Santonja-Renedo, S.; Cejudo, A.; Ayala, F.; Ferrer, V.; Pastor, A.; Collazo-Diéguez, M.; Rodríguez-Ferrán, O.; Andújar, P.; Sainz de Baranda, P. Straight Leg Raise Test: Influence of LumbosantC and Assistant Examiner in Hip, Pelvis Tilt and Lumbar Lordosis. Symmetry 2020, 12, 927. [CrossRef]

72. Witvrouw, E.; Van Tiggelen, D.; Willems, T. Risk Factors and Prevention of Anterior Knee Pain. In Anterior Knee Pain and Patellar Instability; Springer: London, UK, 2006. 
73. Fousekis, K.; Tsepis, E.; Poulmedis, P.; Athanasopoulos, S.; Vagenas, G. Intrinsic Risk Factors of Non-Contact Quadriceps and Hamstring Strains in Soccer: A Prospective Study of 100 Professional Players. Br. J. Sports Med. 2011, 45, 709-714. [CrossRef] [PubMed]

74. Fagerland, M.; Hosmer, D. A Generalized Hosmer-Lemeshow Goodness-of-Fit Test for Multinomial Logistic Regression Models. Stata J. 2012, 12, 447-453. [CrossRef]

75. Coombes, B.; Bisset, L.; Vicenzino, B. Efficacy and Safety of Corticosteroid Injections and Other Injections for Management of Tendinopathy: A Systematic Review of Randomised Controlled Trials. Lancet 2010, 376, 1751-1767. [CrossRef]

76. Cortes, C.; Mohri, M. AUC Optimization vs. Error Rate Minimization. Adv. Neural Inf. Process. Syst. 2004, 16, 313-320.

77. Purcell, L.; Micheli, L. Low Back Pain in Young Athletes. Sports Health 2009, 212-222. [CrossRef]

78. Sadeghisani, M.; Manshadi, F.; Kalantari, K.; Rahimi, A.; Namnik, N.; Karimi, M.; Oskouei, A. Correlation between Hip Rotation Range-of-Motion Impairment and Low Back Pain. A Literature Review. Ortop. Traumatol. Rehabil. 2015, 17, 455-462. [CrossRef]

79. Stuart, M.; Smith, A. Injuries in Junior A Ice Hockey: A Three-Year Prospective Study. Am. J. Sports Med. 1995, 23, 458-461. [CrossRef]

80. Kujala, U.; Salminen, J.; Taimela, S.; Oksanen, A.; Jaakkola, L. Subject Characteristics and Low Back Pain in Young Athletes and Nonathletes. Med. Sci. Sports Exerc. 1992, 24, 627-632. [CrossRef]

81. Butler, D.; Moseley, G. Explain Pain Course Description, 2nd ed.; Noigroup Publications: Adelaide, Australia, 2013.

82. Fridén, J.; Lieber, R. Eccentric Exercise-Induced Injuries to Contractile and Cytoskeletal Muscle Fibre Components. Acta Physiol. Scand. 2001, 171, 321-326. [CrossRef] [PubMed]

83. Asplund, C.; St Pierre, P. Knee Pain and Bicycling Fitting Concepts for Clinicians. Phys. Sportsmed. 2004, 32, 23-30. [CrossRef] [PubMed]

84. Clarsen, B.; Krosshaug, T.; Bahr, R. Overuse Injuries in Professional Road Cyclists. Am. J. Sports Med. 2010, 38, 2494-2501. [CrossRef] [PubMed]

85. Hogg, J.; Schmitz, R.; Nguyen, A.; Shultz, S. Lumbo-Pelvic-Hip Complex Passive Hip Range-of-Motion Values Across Sex and Sport. J. Athl. Train. 2018, 53, 560-567. [CrossRef] [PubMed]

86. Hahn, T.; Foldspang, A.; Vestergaard, E.; Ingemann-Hansen, T. Active Knee Joint Flexibility and Sports Activity. Scand. J. Med. Sci. Sports 1999, 9, 74-80. [CrossRef]

87. Oberg, B.; Ekstrand, J.; Moller, M.; Gillquist, J. Muscle Strength and Flexibility in Different Positions of Soccer Players. Int. J. Sports Med. 1984, 5, 213-216. [CrossRef]

88. Bloomfield, J.; Polman, R.; O’Donoghue, P. Physical Demands of Different Positions in FA Premier League Soccer. J. Sports Sci. Med. 2007, 6, 63-70.

89. Cejudo, A.; Robles-Palazón, F.; Ayala, F.; De Ste Croix, M.; Ortega-Toro, E.; Santonja, F.; Sainz de Baranda, P. Age-Related Differences in Flexibility in Soccer Players 8-19 Years Old. PeerJ 2019, e6236. [CrossRef]

90. De la Fuente, A.; Gómez-Landero, L. Motor Differences in Cadet Taekwondo Athletes According to Competition Level. Rev. Int. Med. y Ciencias la Act. Fis. y del Deport. 2019, 19, 63-75. [CrossRef]

91. Minkoff, J.; Varlotta, G.; Simonson, B. Ice Hockey; Lippincott, Williams \& Wilkins: Baltimore, MD, USA, 1994.

92. Upjohn, T.; Turcotte, R.; Pearsall, D.; Loh, J. Three-Dimensional Kinematics of the Lower Limbs during Forward Ice Hockey Skating. Sports Biomech. 2008, 7, 206-221. [CrossRef]

93. Perrey, S.; Millet, G.; Candau, R.; Rouillon, J. Stretch-Shortening Cycle in Roller Ski Skating: Effects of Technique. Int. J. Sports Med. 1998, 19, 513-520. [CrossRef] [PubMed]

94. Harris-Hayes, M.; Sahrmann, S.; Van Dillen, L. Relationship between the Hip and Low Back Pain in Athletes Who Participate in Rotation-Related Sports. J. Sport Rehabil. 2009, 18, 60. [CrossRef] [PubMed]

95. Cibulka, M.; Strube, M.; Meier, D.; Selsor, M.; Wheatley, C.; Wilson, N.; Irrgang, J. Symmetrical and Asymmetrical Hip Rotation and Its Relationship to Hip Rotator Muscle Strength. Clin. Biomech. 2010, 25, 56-62. [CrossRef] [PubMed] 
96. Kersting, U.; Oliveira, A.; Hansen, J.; Thimm, M.; Lysdal, F.; Mortensen, K.; Haase, J. A Testing Battery on Balance and Performance Symmetry for Team Sports-an Example from Ice Hockey. ISBS Proceedings Archive. 2017, 35, 745-747.

97. Peterson, F.; Kendall, E.; Geise, P. Kendall's Músculos. Pruebas, Funciones y Dolor Postural; Marbán: Madrid, Spain, 2005.

98. Tansey, P. Hip and Low Back Pain in the Presence of Femoral Anteversion: A Case Report. Man. Ther. 2015, 20, 206-211. [CrossRef]

99. Choi, B.; Verbeek, J.; Wai-San Tam, W.; Jiang, J. Exercises for Prevention of Recurrences of Low-Back Pain. Cochrane Database Syst. Rev. 2010, 1. [CrossRef]

(C) 2020 by the authors. Licensee MDPI, Basel, Switzerland. This article is an open access article distributed under the terms and conditions of the Creative Commons Attribution (CC BY) license (http://creativecommons.org/licenses/by/4.0/). 